\title{
CONSIDERAÇÕES IMUNOLÓGICAS SOBRE A PATOGENIA DA INFECÇÃO PELO SARS-COV-2
}

\section{IMMUNOLOGICAL CONSIDERATIONS ON THE PATHOGENESIS OF SARS-COV-2 INFECTION}

Leonardo Pessanha Cordeiro'; Isabel Ribeiro Gomes de Queiroz Crespo'; Maria Luisa Barcelos Falcão'; Yasmim de Souza Leite'; Isadora Enne Magalhães'; Valmir Laurentino Silva².

${ }^{1}$ Acadêmico(a), membro da Liga de Imunologia, Faculdade de Medicina de Campos - FMC, Fundação Benedito

Pereira Nunes, Campos dos Goytacazes, Rio de Janeiro, Brasil.

2 Doutor em Ciências e Professor de Imunologia Básica e Imunologia Médica da Faculdade de Medicina de

Campos- FMC, Fundação Benedito Pereira Nunes, Campos dos Goytacazes, Rio de Janeiro, Brasil.

Endereço para correspondência: Fundação Benedito Pereira Nunes. Avenida Dr. Alberto Torres, 217, Centro, Campos dos Goytacazes RJ- 28035582; e-mail: valmir-silva@fmc.br

\section{RESUMO}

Nas últimas décadas, infecções por coronavírus representaram uma ameaça global à saúde pública. Onovo coronavírus, SARS-CoV-2, que surgiu em Dezembro de 2019, levou poucos meses para provocar o surto da nova doença (COVID-19) declarada como pandemia pela Organização Mundial da Saúde (OMS). SARS-CoV-2 se dissemina, inicialmente, pelo trato respiratório com linfopenia e hipercitocinemia, características de desregulação imunitária, apresentando uma variação de respostas clínicasentre os indivíduos, as quais se agravam com a insuficiência respiratória, que pode cursar com falência de múltiplos órgãos. Devido à possibilidade de exacerbação das respostas imunes, o propósito desta revisão consistiuem uma abordagem imunopatológica frente à infecção pelo SARS-CoV-2. Para tal, a metodologia consistiu em revisão descritiva da literatura, pautada na análise de artigos disponibilizados nas bases de dados mais empregadas. Foram selecionados artigos publicados entre os anos de 2003 a 2020 referentes à imunopatologia da COVID-19. A produção de conhecimento desde o início da pandemia acerca da resposta imunitária ao SARS-CoV-2 aponta que, em indivíduos infectados, a proliferação viral e o dano tecidual ocorrem para além do tecido pulmonar.Dentre os achados sistêmicos foi demonstrado lesão do tecido linfático submucoso do trato gastrointestinal, hemorragias focais renais, edema e degeneração neuronal, degeneração de hepatócitos, manifestações cardiovasculares, hematológicas, cutâneas e obstétricas.

Palavras Chave: SARS-CoV-2; COVID-19; imunopatologia; citocinas; extrapulmonar

\section{ABSTRACT}

In the past few decades, coronavirus infections have posed a global threat to public health. The new coronavirus, SARS-CoV-2, which appeared in December 2019, took a few months to trigger the outbreak of the new disease (COVID-19) declared a pandemic by the World Health Organization (WHO). SARS-CoV-2 initially spreads through the respiratory tract with lymphopenia and hypercytokininemia, characteristics of immune dysregulation, presenting a variation in clinical responses between individuals, which worsen with respiratory failure, which can lead to multiple organ failure. Due to the possibility of exacerbation of immune responses, the purpose of this review was an immunopathological approach to the infection by SARS-CoV-2. To this end, the methodology consisted of a descriptive literature review, based on the analysis of articles available in the most used databases. Articles published between the years 2003 to 2020 referring to the immunopathology of COVID-19 were selected. The production of knowledge since the beginning of the pandemic about the immune response to SARS-CoV-2 points out that, in infected individuals, viral proliferation and tissue damage occur beyond the lung tissue. Among the systemic findings, lesion of the submucosal lymphatic tissue of the gastrointestinal tract, renal focal hemorrhages, edema and neuronal degeneration, hepatocyte degeneration, cardiovascular, hematological, cutaneous and obstetric manifestations were demonstrated.

Ke ywords: SARS-CoV-2; COVID-19; immunopathology; cytokines; extrapulmonary 


\section{INTRODUÇÃO}

A doença infecciosa do coronavírus pandêmico (COVID-19, do inglês Coronavirus Disease 2019), causada pelo Coronavírus 2 da Síndrome Respiratória Aguda Grave (SARS-CoV-2), se expandiu rapidamente em todo o mundo como emergência médica e crise global (ONYEAKA et al. 2020). Coronavírus representam uma família de vírus de RNA envelopados amplamente distribuídos em humanos e animais que causam doenças agudas e crônicas. Das seis espécies de coronavírus conhecidas por causar doenças humanas, quatro geralmente causam sintomas comuns e duas, Coronavírus da síndrome Respiratória Aguda Grave (SARS-CoV) e Coronavírus da Síndrome Respiratória no Oriente Médio (MERS-CoV), podem causar doença respiratória fatal (Peiris et al. 2003; Graham et al. 2013).

O SARS-CoV-2 é um vírus classificado como Betacoronavírus, RNA de fita simples positiva, não segmentado e envelopado. Pertencente ao gênero Coronavirus, família Coronaviridae e subfamília Orthocoronavirinae. O genoma de aproximadamente $30 \mathrm{~kb}$ se assemelha ao de outros coronavírus (Chan et al. 2020) e codifica para quatro proteínas estruturais: as proteínas $\mathrm{S}$ (spike), E (envelope), M (membrana) e $\mathrm{N}$ (nucleocapsídeo) necessárias para formar a partícula completa do vírus (Yan et al. 2020).

As consequências clínicas da infecção por SARS-CoV-2 têm se apresentado de maneira bastante variável, desde uma evolução benigna a uma doença rapidamente fatal nas primeiras 2 a 3 semanas após o início dos sintomas (Boechat et al. 2020). Enquanto muitos indivíduos infectados podem apresentar-se assintomáticos (Lu et al. 2020; Hoehl et al. 2020) ou com apenas sintomas respiratórios superiores, outros desenvolvem pneumonia intersticial que pode rapidamente evoluir com insuficiência respiratória e SARS, necessitando de ventilação mecânica invasiva e admissão em cuidados intensivos, podendo evoluir com falência de múltiplos órgãos (Grasselli et al. 2020; Lippi et al. 2020; Zhu et al. 2020).

A resposta imune ao SARS-CoV-2 se dá logo após a sua entrada nas células hospedeiras, através de diversos mecanismos inatos que, geralmente controlam a propagação da infecção viral, mediante fagocitose e ações citotóxicas sobre as células alvo. Com a persistência da infecção, células dendríticas e a produção de citocinas por vários tipos celulares, iniciam à resposta adaptativa por linfócitos $T$ e $B$, seja para o controle da infecção com clearance viral, ou podem conduzir para uma exacerbação das lesões (imunopatologia), que corresponde ao principal propósito a ser abordado neste artigo de revisão.

MÉTODOS

Trata-se de uma revisão de literatura descritiva, pautada na análise das informações disponíveis em artigos disponibilizados nas bases de dados da plataforma Scientific Electronic Library Online (SciELO), Google Scholar (Google Acadêmico), Portal de Periódicos CAPES, PubMed e ClinicalKey. Quanto aos critérios de inclusão, foram selecionados artigos publicados entre os anos de 2003 a 2020, que abordam as influências imunopatológicas na infecção peloSARS-CoV-2.

\section{RESULTADOSE DISCUSSÃO}

Interações Moleculares do SARS-COV-2 com Células Hospedeiras

A enzima conversora da angiotensina 2 (ACE2 do inglês angiotensin-converting enzyme 2) compartilha $40 \%$ de identidade e $61 \%$ de semelhança com o ACE (Tipnis et al. 2000). A molécula ACE2 foi inicialmente identificada como um receptor de entrada para SARS-CoV e Coronavírus Humano NL63 (HCoV-NL63) (Li et al. 2007; He et al. 2006). Considerando a diferença de sítios ativos entre ACE2 e ACE, as funções dessas duas enzimas são distintas. Diferentemente da $\mathrm{ACE}$, que converte angiotensina I (Ang I) em angiotensina II (AngII), a ACE2 converte Angll em Angiotensina 1-9 (Ang 1-9) (Batlle et al. 2012; Donoghue et al. 2000).

A ACE2 além de se expressar nos tecidos, renais, cardiovasculares e gastrointestinais (Harmer et al. 2002; Tipnis et al. 2000), também está presente nas células epiteliais alveolares, enterócitos do intestino delgado, células endoteliais arteriais e venosas e células do músculo liso arterial (Hamming et al. 2004).

As proteínas $\mathrm{S}$ e $\mathrm{N}$ realizam funções essenciais na patogenia da Covid-19. SARS-Cov-2 utiliza a sua proteína $S$ para se ligar à ACE2, expressa principalmente em células epiteliais alveolares tipo II (AT2 do inglês alveolar epithelial type II) as mais predispostas à infecção viral, incluindo tecidos extrapulmonares como células do coração, rins, vasos sanguíneos e trato gastro-intestinal (Yan et al. 2020). Demonstrou-se que o SARS-CoV-2 exibe novos locais de glicosilação na glicoproteína $S$, sugerindo que o vírus pode utilizar diferentes locais de glicosilação para interagir com seus receptores (Kumar et al. 2020). Estudos demonstraram que a proteína $S$ do 
SARS-CoV-2 tem maior afinidade com o receptor ACE2 em comparação com SARS-CoV. Já a proteína $\mathrm{N}$ é responsável pela replicação viral, de maneira que se complexa com o RNA do genoma para construir uma estrutura de capsídeo encontrada no interior do envelope viral (Finlay \& Hancock 2004).

A proteína $M$ é a proteína transmembranarque se apresenta na partícula do vírion de maneira mais abundante e se liga ao nucleocapsídeo. Durante a infecção a proteína $\mathrm{N}$ é intensamente produzida e proporciona elevada imunogenicidade.Já a proteína $E$, é a menor proteína transmembranar entre as demais e, exerce um papel multifuncional na patogênese, fazendo parte do processo de montagem e liberação do vírus no decorrer do processo infeccioso. Outra molécula, denominada hemaglutinina-esterase (HE) constitui parte do envelope e pode auxiliar na entrada e na liberação do vírus mediante interação com as células do hospedeiro (DHAMA et al. 2020; WEISS et al. 2011).

O SARS-CoV-2 se dissemina principalmente pelo contato direto através de gotículas de saliva ou secreção do trato respiratório, quando uma pessoa infectada tosse ou espirra. Após a ligação ao receptor da ACE2 na superfície celular pela glicoproteína S, ele entra no citoplasma celular, onde libera o genoma RNA e se replica, resultando na formação de novas partículas virais. Em seguida, a célula se desintegra e o vírus se espalha para outras células (Paules et al. 2020).

Outro mecanismo patogênico independente da ligação do vírus ao receptor da ACE2 também foi especulado, alegando que o vírus possa se ligar à cadeia beta de porfirinas dos eritrócitos, resultando em distúrbios no metabolismo do heme e liberação de ferro. No entanto, essa hipótese precisa de mais investigação (Read 2020; Wenzhong \& Hualan, 2020).

Influências de Marcadores Genéticos de Suscetibilidade e de Proteção para COVID-19

Os principais genes envolvidos na infecção pelo SARS-CoV-2 são o gene ACE2 e o gene serina protease transmembrana 2 (TMPRSS2). 0 gene ACE 2 está no cromossomo $X$, que é ativo na maioria dos tecidos e amplamente distribuído (Cheng et al. 2020). A expressão de ACE2 em uma variedade de células permite que diversos órgãos sejam infectados por SARS-CoV-2, corroborando com o perfil sistêmico da COVID-19. O gene TMPRSS2 é muito estudado em oncologia na ocorrência do câncer de próstata primário. No entanto, a serina protease TMPRSS2, expressa na superfície das células epiteliais de diferentes tecidos, incluindo os do trato aerodigestivo (Hoffmann et al. 2020), cliva a proteína S de SARSCoV-2 expondo o sítio de ligação à ACE2, evento crucial para a entrada do vírus na célula hospedeira (Stopsack et al. 2020).

Análises em células infectadas com o SARSCoV-2 sugerem que o ACE2 não é apenas um receptor, mas também tem função na regulação pós-infecção, incluindo resposta imune, secreção de citocina e replicação de genoma viral (Li et al. 2020). Coronavírus, bem como o vírus da gripe, dependem da serina protease TMPRSS2 para a entrada e disseminação viral no hospedeiro (Stopsack et al. 2020, Böttcher et al. 2006).

Devido ao gene ACE2 se localizar no cromossomo $X$, pressupõe-se que mulheres, potencialmente heterozigotas, com maior diversidade genética em comparação aos homens que são definitivamente hemizigotos, teriam vantagens para abreviar a progressão da infecção por SARS-CoV-2. Por outro lado, a maior taxa de expressão de ACE2 no sexo feminino, embora controversa, poderia atribuir-Ihes pior prognóstico, o que contraria os dados epidemiológicos mundiais (Li et al. 2020). Vários genes envolvidos na resposta inflamatória estão localizados no cromossomo $X$, que também contém alto número de genes relacionados ao sistema imunitário, responsáveis por respostas imunes inatas e adaptativas à infecção (Gemmati et al 2020). O silenciamento aleatório de um dos cromossomos $X$ em mulheres representa uma vantagem na fase aguda de doenças inflamatórias (Lefevre et al. 2020). Essas condições em conjunto com as funções dos hormônios sexuais parecem ser responsáveis pelo melhor prognóstico da infecção nas mulheres, embora, estudos mostrem a necessidade de uma abordagem multidisciplinar para essa condição (Gemmati et al 2020).

O estrogênio participa nas respostas imunes e pode conferir ação protetora na infecção por SARSCoV-2 (Gemmati et al. 2020). O estrogênio, ou sua forma mais potente, $17-\beta$-estradiol se liga ao receptor intracelular (ER), que sofre alterações conformacionais, transloca-se para o núcleo e se liga aos promotores dos genes-alvo para regular a expressão de fatores de transcrição estimulando a expressão da proteína ativadora 1 (AP-1) e NF-kB (Moulton 2018). O estrogênio ativa monócitos, macrófagos e neutrófilos, induzindo a produção de citocinas pró-inflamatórias e quimiocinas (CHANNAPPANAVAR et al. 2017). Isso leva à ativação 
de outras células, como linfócitos e macrófagos com aumento da produção de interferon do tipo I e III, fundamentais para diminuir a produção de partículas virais (KOVATS 2015). Além disso, esse hormônio aumenta os níveis de expressão do domínio 17 e 10 da metalopeptidase do ADAM (ADAM17 e ADAM10), genes protetores contra eventos cardiovasculares em mulheres, sendo esta, mais uma hipótese para explicar o melhor prognóstico da COVID-19 no sexo feminino (Gemmati et al. 2020).

Efeitos Citopáticos em Pneumócitos e Células Endoteliais Capilares Induzidos por SARSCoV-2.

A infecção das células epiteliais das vias aéreas pelo SAR-CoV-2 ocorredevidoa ação TMPRSS2 e da cisteína endossômica proteases catepsina B e $L$ (CatB / L), responsáveis pela ativação das proteínas $S$ virais, que por sua vez, irão interagir com o receptor ACE2, propiciando assim, a entrada do vírus na célula (Hoffmann et al. 2020; Jia et al. 2005). Nesse contexto, o receptor é internalizado em conjunto com o vírus, reduzindoa sua expressão na membrana celular (Li et al. 2020).

O ACE2 se expressa mais em pneumócitos tipo II se comparado à sua expressão em outras células do epitélio da via respiratória, e apresenta função fisiológica de degradar aang II (Zou et al. 2020). Em um cenário em que há redução dos seus níveis, consequentemente, ocorre aumento da concentração da angiotensina II, que irá intensificar sua ação no receptor de angiotensina II tipo 1 (AT1), uma proteína componente da membrana celular que integra o grupo de receptores acoplados a proteína $\mathrm{G}$ que, ao interagir com a angiotensina II, provoca uma série de reações celulares, sendo uma das mais importantes, a vasoconstrição. Neste contexto, é instalado um quadro de desequilíbrio do sistema renina-angiotensina, prejudicando a função pulmonar, facultando a formação de edema, bem como, dano ao endotélio capilar (Li et al. 2020; Kuba et al 2020; Imai et al. 2020).

No interior dos pneumócitos o vírus irá desempenhar seus efeitos citopáticos passíveis de levar à morte celular e à potencialização da resposta inflamatória (Zhu et al. 2020). Foi observado em diversos exames histopatológicos, descamação do epitélio alveolar e sincícios multinucleados formados por pneumócitos hiperplásicos atípicos, em que se destacam núcleos grandes e citoplasma granular, além disso, em alguns casos, foi verificado metaplasia escamosa de células epiteliais ( $\mathrm{Xu}$ et al. 2020; Adachi et al. 2020; Martines et al. 2020;
Zorzetto 2020; Wichmann et al. 2020)

As células endoteliais capilares também expressam ACE2, desse modo, em um quadro de SARS-CoV-2, essas células também são infectadas. Ainda não estão bem elucidados os efeitos citopáticos do vírus sobre as células endoteliais, no entanto, foi verificada a indução de apoptose e piroptose (um tipo de morte celular inflamatória). É fato que em caso de infecção por SARS-CoV-2 há disfunção endotelial generalizada causada por recrutamento de células imunes, induzida pelo próprio sistema imunitário ou devido infecção viral direta do endotélio. Foi encontrado em exame histopatológico do endotélio vascular pulmonar abundância de células inflamatórias, corpos apoptóticos, congestionamento dos pequenos vasos pulmonarese, em alguns casos, foi evidenciado presença de microtrombos e pequenos focos de hemorragia (Adachi et al. 2020; Zorzetto 2020; Varga et al. 2020).

Desse modo, um quadro pulmonar de infecção por SARS-CoV-2 é caracterizado por dano alveolar difuso exsudativo fibrinoso com células do revestimento alveolar desnudadas, presença de edema pulmonar, depósito de fibrina, formação de membrana hialina e infiltração de células inflamatórias, revelando síndrome do desconforto respiratório agudo (SDRA). Além disso, podem ser observados macrófagos carregados de hemossiderina, hemorragia intravascular, congestão vascular e presença de microtrombos. Supõe-se que as células imunes, além de combaterem as células infectadas, causem danos às células saudáveis, o que justificaria a quebra da barreira mucosa que propicia infecções pulmonares secundaria (Xu et al. 2020; Adachi et al. 2020; Martines et al. 2020; Zorzetto 2020; Wichmann et al. 2020; Menter et al. 2020; Barton et al. 2020).

Resposta Imuno-Inflamatória na COVID-19

Seguramente, a inflamação imunomediada desempenha um papel importante na patogênese da COVID-19, assim como na SARS. As investigações laboratoriais também demonstram níveis plasmáticos elevados de citocinas pró-inflamatórias, como interleucina-1 beta (IL-1 $\beta$ ), interleucina 6 (IL-6), interleucina-8 (IL-8), quimiocinas inflamatórias, incluindo o ligante CC-quimiocina 2 (CCL2), CCL3 e CXC-ligante quimiocina 10 (CXCL10) e fator de necrose tumoral-alfa (TNF- $\alpha$ ), bem como a forma solúvel da cadeia- $\alpha$ do receptor de IL-2. Níveis mais altos de marcadores inflamatórios séricos (proteína 
C-reativa, ferritina e dímeros-D), proteína quimiotática de monócitos-1 (MCP-1) e proteína inflamatória-1 alfa dos macrófagos (MIP-1 $\alpha$ ) (Huang et al. 2020; Wu et al. 2020). A contagem reduzida de linfócitos e níveis elevados de ferritina, IL-6 e dímero $\mathrm{D}$ foram relatados em vários estudos associado-os ao aumento da mortalidade por COVID-19 (Qin et al. 2020; Zhou et al. 2020).

A maioria das células inflamatórias infiltradas nos pulmões são monócitos e macrófagos. Os achados de autópsia mostraram a presença destas células inflamatórias e uma quantidade moderada de células gigantes multinucleadas associadas à lesão alveolar difusa. No entanto, os linfócitos infiltrantes pulmonares são escassos e, frequentemente, positivos para CD4. Esses achados não foram diferentes dos relatados para pacientes com infecções por SARS-CoV e MERS-CoV (Xu et al. 2020).

Em pacientes com COVID-19, níveis elevados de dímero-D são importantes e a elevação persistente confere mal prognóstico. O desenvolvimento de doença intravascular disseminada (DIC) é outro problema, caracterizado pelo prolongamento do tempo de protrombina e tempo parcial de tromboplastina ativada, produtos de alta degradação de fibrina e trombocitopenia grave, que pode ser fatal (Yao et al. 2020).

A tendência trombótica em pacientes com COVID-19 é provavelmente causada pela ativação ou dano das células endoteliais devido à ligação viral ao receptor da ACE2. A presença de fatores de risco tradicionais para tromboembolismo venoso foi alta entre os pacientes com COVID-19. Os altos níveis de mediadores inflamatórios e imunoglobulinas podem elevar a densidade sanguínea. A ventilação mecânica e intervenções vasculares, como cateterismo venoso central, podem induzir ainda mais danos endoteliais vasculares em pacientes graves ou gravemente enfermos. Os níveis de anticorpos anticardiolipina também foram elevados em pequenos grupos relatados. A combinação de todos esses fatores pode levar à trombose venosa profunda e ao tromboembolismo pulmonar letal. Portanto, pacientes infectados com SARS-CoV-2, hospitalizados ou ambulatoriais, precisam de profilaxia precoce e prolongada com heparina de baixo peso molecular (Zhang et al. 2020a; Zhang et al. 2020.b). Vale ressaltar, que alterações isquêmicas nos dedos das mãos e pés simulando vasculite foram relatadas em pacientes com COVID-19 grave (Lin et al. 2020).
As células T CD4+ e as células T CD8+ desempenham um papel antiviral importante ao contrabalancear a resposta imune diante do risco de desenvolver auto-imunidade ou exacerbar lesões inflamatórias. As células T CD4+ promovem a produção de anticorpos específicos para o vírus ao ativar células $B T$ dependentes. No entanto, as células T CD8+ são citotóxicas e podem matar células infectadas por vírus. As células T CD8+ representam cerca de $80 \%$ do total de células inflamatórias infiltrativas no interstício pulmonar em pacientes infectados com SARS-CoV e desempenham um papel vital na eliminação de coronavirus em células infectadas, bem como na lesão imunomediada (Maloir et al. 2018).

As evidências laboratoriais assinalam que 0 número de linfócitos T CD4+, CD8+e, especialmente, de células NK, é muito menor nos pacientes que cursam com a doença grave (Zhang et al. 2020a). O número de células $T$ reguladoras (Treg) também é muito baixo. A linfopenia grave é um sinal muito precoce da doença, precedendo os problemas pulmonares, e tende a normalizar na medida em que o paciente melhora. A linfopenia está incluída entre os critérios de diagnóstico na China. Embora os níveis reduzidos de células $T$ circulantes nos pacientes possam refletir seu recrutamento massivo em tecidos inflamados ou o uso de tratamento com esteróides para mitigar a inflamação, alguns estudos relataram depleção significativa de células $T$ dos órgãos linfóides secundários de pacientes infectados com SARS-CoV e SARS-CoV-2 (Gu et al. 2005; Chen et al. 2020). Os mecanismos subjacentes à linfopenia progressiva em pacientes graves com COVID-19 permanecem incertos (Qin et al. 2020). A linfopenia também foi uma característica importante dos pacientes com SARS, e o declínio dos linfócitos T CD4+ e CD8+ muitas vezes precedeu as alterações radiográficas (Li et al. 2004). Ainda que os mecanismos responsáveis pela depleção de células $T$ sejam pouco compreendidos, provavelmente, não estão relacionados à infecção direta de células T pelo vírus, pelo menos no caso de pacientes com COVID-19 para os quais nenhuma evidência apóia a possível infecção de células T por SARS-CoV-2 (Chen et al. 2020). Vale ressaltar que os níveis séricos de TNF, IL-6 e IL-10 correlacionaram-se negativamente com o número de células $\mathrm{T}$, provavelmente sob a influência reguladora da IL-10 (Diao et al. 2020).

Além do baixo número de linfócitos periféricos, há uma atrofia impressionante dos órgãos linfóides secundários, incluindo os nódulos 
linfáticos e o baço, confirmados pelos achados da autópsia. Foram relatados atrofia linfonodal e esplênica associada à necrose, degeneração significativa das células esplênicas, necrose hemorrágica focal, proliferação de macrófagos e aumento da apoptose de macrófagos no baço. A coloração imuno-histoquímica mostrou um número reduzido de células $T$ CD4+ e CD8+ nos nódulos linfáticos e no baço (Xu et al. 2020; Yao et al. 2020).

No momento, nenhuma expressão gênica viral foi observada em células mononucleares do sangue periférico (PBMCs) de pacientes com COVID19 (Xiong et al 2020). No entanto, Wang e colaboradores (2020), indicaram que os linfócitos $T$ podem ser mais permissivos com SARS-CoV-2 do que com SARS-CoV, possivelmente por conta de uma via de endocitose desencadeada pela glicoproteína S. Como a ACE2 não é facilmente expressa nos linfócitos, a eficiência da fusão da membrana e em que medida isso pode explicar a perda geral de linfócitos ainda precisam ser elucidadas. Além disso, Xiong e colaboradores (2020) relataram aumento da apoptose, autofagia e vias de p53 em PBMCs de pacientes com COVID-19. Esses achados indicaram que o distúrbio imunológico começa no início da COVID-19, como resultado combinado dos efeitos diretos e das células espectadoras (celulas adjacentes não específicas que, se estimuladas, amplificam as reações). Embora as observações atuais tenham revelado que essas alterações podem ser amplamente reversíveis (Zheng et al. 2020), especialmente em casos leves ou moderados, é necessário acompanhamento a longo prazo para uma avaliação mais aprofundada da função imunológica em pacientes recuperados.

O sistema complemento desempenha um papel vital na resposta imune do hospedeiro à infecção por coronavírus. Dado seu potencial de danificar os tecidos hospedeiros, o sistema complemento é fortemente controlado inibindo proteínas séricas. Os fragmentos $\mathrm{C} 3 \mathrm{a}$ e $\mathrm{C} 5$ a exibem potentes propriedades pró-inflamatórias e podem desencadear o recrutamento de células inflamatórias e a ativação de neutrófilos. Falhas nos mecanismos reguladores do sistema complemento contribuem para a patogênese do coronavírus na síndrome respiratória aguda grave (Gralinski et al. 2018).

A resposta do anticorpo in vivo representa uma complexa resposta policlonal direcionada para diferentes domínios antigênicos das glicoproteínas do envelope viral. É importante determinar se os anticorpos proporcionam resposta protetora ou facilitadora da infecção. Observa-se, na maioria dos casos de COVID-19, que duas semanas após o início dos sintomas, os títulos de anticorpos são estatisticamente mais altos nos pacientes críticos em comparação aos não críticos, possivelmente, devido à hiperrespostaanticórpica, refletindo observações semelhantes quanto à gravidade da doença em pacientes MERS-CoV e SARS-CoV (Zhao et al., 2020).

Em alguns casos leves, a detecção de anticorpos ocorre depois de muito tempo após o início dos sintomas e, em um pequeno número de casos, os anticorpos não são detectados, pelo menos durante a escala de tempo dos estudos relatados. Há uma escassez de informações sobre a longevidade da resposta do anticorpo ao SARS-CoV-2, mas sabe-se que os anticorpos para outros coronavírus humanos diminuem com o tempo e existem relatos de reinfecção com coronavírus homólogos após apenas 80 dias. Assim, a hipótese de que a reinfecção pode levar à casos brandos de SARS-CoV-2 é uma possibilidade realista que deve ser considerada (Kissler et al., 2020).

Os achados laboratoriais dos primeiros casos de COVID-19 em Wuhan, na China, demonstraram a ocorrência de síndrome de ativação de macrófagos (MAS, do inglês macrophage activation syndrome), tempestade de citocinas e síndrome do desconforto respiratório agudo (SDRA). Não há consenso ou sugestão sobre qual terminologia deve ser usada: tempestade de citocinas, MAS, síndrome hemofagocítica, ou linfo-histiocitose hemofagocítica ( $\mathrm{HLH}$, do inglês h e mophagocytic lymphohistiocytosis) secundária, síndrome de liberação de citocinas (CRS, do inglês cytokine release syndrome) ou simplesmente hipercitocinemia, relacionada à hiperativação imunitária, que desencadeia um estado hiperinflamatório, levando aos sinais e sintomas da síndrome, como febre alta prolongada, hepatoesplenomegalia e citopenias, marcados por níveis muito altos de citocinas séricas pró-inflamatórias e ferritina. Antes do surgimento da COVID-19, níveis séricos significativamente mais elevados de IL-6, IFN- $\alpha$, CCL5, CXCL8 e CXCL10 também foram detectados em pacientes com infecções graves por SARS-CoV ou MERS-CoV em comparação com aqueles com infecções mais leves (Min et al. 2016).

'Os fatores predisponentes propostos para MAS e tempestade de citocinas secundários à infecção por SARS-CoV-2 compreendem depuração viral prejudicada (Snijder et al. 2006), desregulação 
das respostas do interferon tipo I (Acharya et al. 2020), armadilhas extracelulares de neutrófilos (Kaplan \& Radic 2012) entre outros mecanismos, como a piroptose (Yang 2020; Bergsbaken et al. 2009) e a participação de anticorpos facilitadores da infecção (Golonka et al. 2020).

'A depuração viral prejudicada na COVID-19, assim como nas infecções por SARS-CoV e MERS-CoV consiste em fator agravante da infecção. Estes vírus, assim como outros biopatógenos, desenvolvem estratégias de evasão da resposta imunitária. OSARSCoV e o MERS-CoV produzem vesículas com membranas duplas sem Receptores de Reconhecimento de Padrões (PRRs) e replicam dentro dessas vesículas (Snijder et al. 2006). Essas estratégias levam à resposta imune antiviral e a depuração viral prejudicadas.

Se por um lado a infecção com SARS-CoV-2 pode levar à produção excessiva de citocinas próinflamatórias, por outro lado, a produção de interferons do tipol, principais mediadores antivirais, é supostamente prejudicada. A CRS provocada pelo SARS-CoV-2 lembra a desregulação imunológica causada por outros vírus respiratórios altamente patogênicos, incluindo os betacoronavírus SARS-CoV e MERS-CoV (Acharya et al. 2020). As respostas desreguladas do IFN são indicativas das estratégias imunomoduladoras usadas pelos betacoronavírus. Durante a fase de incubação, o SARS-CoV-2 se replica furtivamente nas células hospedeiras livres da ativação de IFNs, levando a altas cargas virais (BlancoMelo et al. 2020).

Como visto anteriormente, coronavírus induzem a formação de compartimentos membranosos dedicados à síntese de RNA viral e, assim, ocultam osPadrões Moleculares Associados à Patógenos(PAMPs), por exemplo, RNAs virais, da detecção por PRRs do hospedeiro, como RIG-I e MDA5. Além disso, sabe-se que várias proteínas conservadas de betacoronavírus, proteínas predominantemente não estruturais, exercem atividades antagônicas diretas ao IFN. Alguns modificam características específicas do RNA viral para evitar o reconhecimento por PRRs específicos, enquanto outros inibem a transdução de sinal mediada por PRRs (Channappanavar et al, 2016). Por outro lado, a proteína nucleocapsídica do SARS-CoV demonstrou ativar diretamente o NF-kB. A produção robusta de citocinas e quimiocinas pró-inflamatórias, com uma produção limitada de IFNs, durante a infecção por SARS-CoV-2 sugere ativação eficaz de NF-KB, mas não a do fator-3 regulador de IFN (IRF3 do inglês Interferon Regulatory Factor-3) e IRF7, fundamentais para conter infecções virais (BlancoMelo et al. 2020).

COVID-19 grave está associada a respostas de células $T$ deficitárias que se manifestam como linfopenia e esgotamento funcional das células $T$ CD4+ e CD8+ (Zheng et al. 2020). As respostas prejudicadas das células $T$ podem resultar da produção deficiente de IFN, já que os IFNs promovem a sobrevivência e as funções efetoras das células $T$. Embora a produção precoce de IFNs seja crucial para uma resposta eficiente das células $T$, uma resposta tardia do IFN pode inibir a proliferação de células Tou a saída de células $T$ dos órgãos linfáticos, ou pode causar exaustão funcional e morte celular das células $T$ (Qin et al. 2020).

Os neutrófilos podem reter e destruirbiopatógenos, incluindo vírus, não apenas pela fagocitose com formação de espécies reativas de oxigênio, pela degranulação e secreção de antimicrobianos, mas também pela formação de "armadilhas" extracelulares dos neutrófilos (NETs, do inglês neutrophil extracellular traps). NETs são redes de fibras extracelulares, compostas principalmente de DNA de neutrófilos que se ligam e matam patógenos extracelulares com redução de danos às células hospedeiras (Kaplan \& Radic 2012).

A piroptoseé um tipo de morte celular programada, inflamatória, caspase-dependente, que se diferencia em vários aspectos da apoptose, e ocorre com mais frequência, após infecção por patógenos intracelulares (Tait et al. 2014). A piroptose se caracteriza pela lise da membrana plasmática e liberação de conteúdo intracelular inflamatório. A rápida replicação viral leva ao aumento da piroptose e pode provocar a liberação maciça de mediadores inflamatórios, exercendo um papel importante na patogênese do COVID-19 (Yang 2020; Bergsbaken et al. 2009).

Anticorpos contra a glicoproteína S (anti-SIgG) podem causar alterações patológicas, responsáveis por lesões pulmonares mediadas por vírus (Liu et al. 2019). Golonka e colaboradores especularam que a glicoproteína $\mathrm{S}$ nos coronavírus pode sofrer uma alteração conformacional e entrar nas células hospedeiras utilizando a região $\mathrm{Fc}$ da IgG complexada. Em outras palavras, eles propuseram um mecanismo que permite a entrada viral nas células hospedeiras mediada por anticorpos (Golonka et al. 2020).

Mecanismos Imunológicos Associados à Patogênese Extrapulmonar da COVID-19 
Autópsias de pacientes infectados com SARS-CoV confirmado por RT-PCR já mostraram que a proliferação e dano dos coronavirusse dão além do tecido pulmonar. Dentre os achados sistêmicos foi demonstrado lesão do tecido linfático submucoso do trato gastrointestinal (TGI), hemorragias focais renais, edema e degeneração neuronal, degeneração de hepatócitos, assim como a presença do vírus nas células epiteliais do intestino e túbulos renais através de hibridização in situ e no cérebro por microscopia eletrônica (Gu et al. 2005). Coronavirus compartilham $54 \%$ de todo seu genoma o que pode embasar os achados extrapulmonares recentemente adereçados ao SARS-CoV-2 (Behzad et al. 2020; Chen etal.2020).

\section{Manifestações Cardiovasculares}

A ACE2 está relacionada a mecanismos cardioprotetores como a diminuição do remodelamento cardíaco, já sua deficiência está ligada a instabilidade plaquetária. Após a interação com o SARS-CoV-2, a ACE2 é internalizada, o que pode sugerir parte dos eventos cardiovasculares atrelados a COVID-19 somado ao aumento de angiotensina II nos infectados, nos quais a presença de doença cardiovascular prévia sugere maior gravidade da doença. Ainda não há evidência se a manutenção da terapia com inibidores da enzima conversora de angiotensina (IECA) ou bloqueadores do receptor de angiotensina (BRA) confere maior risco em infectados pela suprarregulação de ACE2 ou se sua interrupção confere maior risco pela desregulação cardiovascular em pacientes já cardiodebilitados. Estudos retrospectivos mostram menor ou igual mortalidade entre pacientes em uso de IECA/BRA em relação a grupos controles e a recomendação da American Heart Association (AHA) é em favor da manutenção da terapêutica (Albini et al. 2020; Marchand ot et al. 2020; Madjid et al. 2020).

Níveis elevados de D-dímero e produtos da degradação da fibrina têm sido relatados como fatores de mal prognóstico para a Covid-19, bem como o aumento do Fator Von Willebrand, trombocitopenia e aumento do tempo de tromboplastina parcial ativada. Segundo (Marchandot et al. 2020) tais alterações hemostáticas podem ser explicadas pelo excesso de produção de trombina, interrupção precoce da fibrinólise induzida pela infecção viral, estímulos prótrombóticos em vigência da hipóxia grave e mecanismos pulmonares próprios.

Casos mais graves de COVID-19 estão intimamente ligados ao fenômeno de tempestade de citocinas, comhiper-expressãode citocinas de fase aguda como IL-1 $\beta$, IL- 6 e TNF- $\alpha$, além de proteína 10 induzida por INF- $\gamma$ (IP-10) e MCP-1 que, em conjunto, podem contribuir para o estímulo pró-trombótico, somado a perda de estímulos anti-inflamatórios e vasodilatadores promovidos pelo ACE2 endotelial agora internalizado pela interação viral (Marchandot et al. 2020; Troyer et al. 2020).

Uma explicação para a maior susceptibilidade de pacientes cardiopatas pode ser a maior expressividade de ACE2 no miocárdio lesado. Estudos retrospectivos já mostraram taxas significativamente maiores de marcadores de lesão miocárdica como mioglobina, fração $M B$ da creatinaquinase (CK-MB) e troponina I em pacientes não sobreviventes pareados com grupo sobrevivente. Já foram relatados casos de miocardite na COVID-19 e dados de autópsias já revelaram a presença de infiltrado mononuclear em miocárdios de infectados (Marchandot et al. 2020; Madjid 2020; Su et al. 2020).

\section{Manifestações Hepáticas}

Embora elevações em marcadores de lesão hepática já tenham sido relatadas, pouca evidência há disponível acerca de sua patogenicidade. 0 receptor ACE2 encontra-se bem expresso nos colangiócitos, em proporções semelhantes a dos pneumócitos, no entanto, sua presença nos hepatócitos parece ser encontrada em menos de $3 \%$ das células, o que dificulta o entendimento da elevação da alanina aminotransferase (ALT), aspartato aminotransferase (AST), bilirrubina e hipoalbuminemia em coortes recentes. Da mesma forma, a umento discrepante de gamaglutamiltransferase (GGT) com valores frequentemente normais de fosfatase alcalina somam-se a falta de explicações razoáveis ao dano cole-hepático do vírus. Propõe-se ligação entre a tempestade de citocinas e lesão hepática já que níveis elevados de proteína $C$ reativa (PCR) e linfopenia estão mais presentes em pacientes que desenvolveram injuria hepática. A presença de doenças hepáticas pré-existentes como a Hepatite $B$ e cirrose podem ser indicativos de infecção mais grave, no entanto poucos estudos foram feitos e tal associação ainda tem pouco suporte (Musa 2020; Morgan et al. 2020; Peng et al. 2020).

Além disso, não é possível afirmar que o dano hepático seja gerado por mecanismos infecciosos/inflamatórios ou se são apenas 
consequência do uso de fármacos hepatotóxicos como o Acetominofeno,Azitromicina e Ritonavir.Até o momento não foram encontrados sinais de inclusão viral hepática em autópsias, no entanto,a presença de hepatomegalia com degeneração dos hepatócitos, necrose lobular focal e infiltrado inflamatório composto por neutrófilos, monócitos e linfócitos foi evidenciada (Musa 2020; Morgan et al. 2020; Li \&Fan 2020).

\section{Manifestações Gástricas}

ACE2 está bem expressa nas células epiteliais do duodeno, íleo e do cólon, células glandulares do estômago e no esôfago. Tal expressão é ainda maior em pacientes com adenomas e câncer colorretal. É sugerido que ACE2 participe de regulação da imunidade inata, da atividade citotóxica celular e do metabolismo energético. Assim, pode servir como base para infecção local e explicar os casos de diarreia, dor abdominal, náuseas e vômitos relatados em pacientes com COVID-19. Associação estatística já foi feita entre a presença de sintomas intestinais e maior tempo de internação. Não pode ser desconsiderada a utilização de antibióticos como parte dos mecanismos envolvidos nos sintomas gastrointestinais (Musa 2020; Li et al. 2020; Pan et al. 2020).

Embora o vírus já tenha sido detectado em amostras de fezes ainda não se sabe se a transmissão oro-fecal é possível. Amostras fecais podem conter o vírus por até 5 semanas após sua presença não ser mais detectada no trato respiratório. Essa possibilidade reforça a necessidade ainda maior de higiene hospitalar e urbana (Zhang et al. 2020; Wu et al. 2020).

\section{Manifestações Renais}

Uma coorte com 701 pacientes mostrou associação estatística entre a presença de elevação da creatinina sanguínea e maior tempo de internação, bem como maior mortalidade. Nesses pacientes $43,9 \%$ apresentaram proteinúria e $26,7 \%$ apresentaram hematúria. Lesão renal aguda foi detectada em $5,1 \%$ dos pacientes. $O$ receptor ACE 2 está expresso nos podócitos e nos túbulos proximais e pode explicar a lesão renal nesses pacientes, associada também a sepse, choque e falência múltipla de órgãos (Adapa et al. 2020; Cheng et al. 2020).

O vírus já foi detectado em amostra de urina e nas células glomerulares. Dados de autópsia mostram também diversos sinais inflamatórios como agregados eritrocitários, infiltrado de linfócitos e macrófagos, degeneração vacuolar e dilatação do lúmen tubular com debris celulares. Imunoglobulinas IgM, IgA e IgG, assim como C3, foram observadas por imunofluorescência em tecido renal (Puelles et al. 2020; Sun et al. 2020; Su et al. 2020).

\section{Manifestações Neurológicas}

Coronavírus pode ter acesso ao sistema nervoso central através da corrente sanguínea ou via retrógrada neuronal. Esta situação pode levar ao quadro de meningite e encefalite com risco de morte. A encefalite viral pode ser leve, moderada ou grave. Na manifestação leve, o paciente pode não ser diagnosticado devido a sintomas sutis ou inexistentes. Por outro lado, a encefalite grave pode se apresentar mediante estado mental alterado, alucinações, mudança de comportamento, alterações na fala movimento motor anormais, e anormalidades neurológicas focais, como paralisia flácida, parestesia, hemiparesia ou convulsões (Desforges et al. 2020).

Os exames do líquido cefalorraquidiano em pacientes com infecção por SARS-CoV-2 confirmaram a presença do RNA viral. Além disso, estudos em ratos concluíram que a infecção por SARS-CoV-2 pode causar a morte de ratos ao invadir o tecido cerebral.

Baig e colaboradores (2020) relataram invasão neurológica na pneumonia por COVID-19 ao demonstrarem que SARS-CoV-2 pode penetrar no SNC através da circulação sistêmica ou através da placa cribriforme do osso etmóide. O SARS-CoV-2 pode subsequentemente causar danos aos tecidos neuronais, interagindo com os receptores ACE2. O envolvimento cerebral de COVID-19 via placa cribriforme pode levar a complicações adicionais, como hiposmia ou anosmia (Fodoulian et al. 2020; Baig et al. 2020). Este estudo também mencionou a possibilidade de ruptura endotelial cerebrovascular levando a sangramento e complicações fatais (Baig et al. 2020), e acidente vascular cerebral devido a hemorragia intracerebral com sequela neurológica (Sharifi-Razavi et al. 2020).

Em estudo semelhante, Poyiadji e colaboradores (2020) descreveram encefalopatia necrosante hemorrágica aguda associada à COVID-19 em um paciente com estado mental alterado cujo teste molecular de PCR apresentou resultado positivo para SARS-CoV-2. Os achados de imagem foram relatados como hipoatenuação simétrica na região talâmica bilateral medial observada na Tomografia Computadorizada (TC) da cabeça e lesões 
que aumentam a borda hemorrágica no talâmico bilateral, lobos temporais mediais e regiões subinsulares observados na Ressonância Magnética (RM)cerebral do paciente (Poyiadji et al. 2020).

Embora as manifestações neurológicas por COVID-19 ainda estejam em estudo, existe grande possibilidade do real envolvimento do SNC em alguns pacientes, principalmente aqueles que sofrem da forma grave da doença. Desta forma, a notificação no prontuário de maneira precisa e direcionada quanto aos sinais e sintomas neurológicos, investigações clínicas neurológicas e eletrofisiológicas detalhadas dos pacientes, são de extrema importância. Além disso, tentativas de isolamento do SARS-CoV-2 do líquido cefalorraquidiano e autópsias das vítimas de COVID-19 podem esclarecer os papeis desempenhados por esse vírus nas manifestações neurológicas.

\section{Manifestações Hematológicas}

A falência de múltiplos órgãos, uma das graves complicações da COVID-19, resulta da superprodução de citocinas pró-inflamatórias associada à reduzida capacidade de oxigenação do sangue. Choque séptico, acidose metabólica de difícil correção e disfunção da coagulação incluem outras complicações observadas nos casos graves. $O$ início precoce da contagem normal diminuída de glóbulos brancos ou diminuição da contagem de linfócitos (linfopenia) é frequentemente observado em pacientes com COVID-19 (Liu et al. 2020; Wang et al. 2020).

Linfopenia foi demonstrada nos órgãos hemato-linfoides no exame post-mortem. A análise multivariada mostrou que a idade avançada e alta concentração de lactato desidrogenase foram preditores independentes de resultado adverso. Subtipos de linfócitos do sangue periférico foram analisados por Wong e colaboradores em 31 pacientes com SARS. As contagens de células T CD4+ e CD8+ caíram logo no início da doença (Wong et al. 2020) e declinam em maior grau quando comparadas com infecções por Citalomegavírus (CMV), Virus Epstein-Barr (EBV) e Vírus da Imunodeficiência Humana (HIV) (Li et al. 2020). Com base nestes resultados estes pesquisadores concluíram que variáveis hematológicas anormais foram comuns em pacientes com SARS de modo que a linfopenia e a depleção dos subtipos de linfócitos T podem estar associadas à atividade da doença (Wong et al. 2020). Ao analisar o sangue periférico de pacientes que vieram à falecer por COVID-19 foi detectado por citometria de fluxo que as contagens de linfócitos T CD4+ e T CD8+ estavam diminuídas, enquanto a proporção de HLA-DR e CD38 fração duplo positiva foi alta, o que indica status de hiperatividade das células T. Além disso, uma concentração elevada de CCR4+e CCR6+ foi encontrada nas células T CD4+ indicando um perfil Th17 e altas expressões de grânulos citotóxicos nas células T CD8+, comprovando a superativação dos linfócitos T (Xu et al. 2020).

A ACE 2 possui papel regulador na hematopoiese (Haznedaroglu \& Beyazit 2013). Foi demonstrado em um modelo experimental com células tumorais e em um modelo de inflamação crônica induzida por adjuvante completo Freund, que o aumento da expressão da ACE nas células mielóides facilitou a maturação e diferenciação destas células, tendendo para um fenótipo pró-inflamatório (células mielomonocíticas e macrófagos), e inibiu o desenvolvimento de células supressoras mielóides derivadas (MDSCs). Este estudo propôs que a infecção por SARS-CoV-2 interfere na redução da ACE2 e no aumento da expressão da ACE em precursores mielóides, o que potencialmente, facilita a maturação mielóide e torna os macrófagos mais pró-inflamatórios, com consequente redução de MDSCs e da ativação das células $T$, agravando a resposta imune frente às células alvo e com maior consumo das células T CD4+ e T CD8+ (Shen et al. 2020).

Em relação à neutrofilia, alguns estudos demonstraram maior chance de evidência nos pacientes de UTI, o que indica mal prognóstico (Huang et al. 2020; Wang et al. 2020; Liu et al. 2020). No início do COVID-19, foi observado que os não sobreviventes desenvolveram mais linfocitopenia grave e maior contagem de neutrófilos, quando comparados com os sobreviventes (Wang et al. 2020). Uma regressão bivariada de Cox, modelo muito útil para avaliar o efeito conjunto das variáveis independentes na sobrevida de um indivíduo, confirmou que a neutrofilia está associada ao desenvolvimento de SDRA e à progressão para óbito (Wu et al 2020)

A trombocitopenia é apresentada em quase todos os pacientes com COVID-19. Análises demonstraram que os casos graves foram mais susceptíveis à trombocitopenia quando comparados aos não graves (Guan et al. 2020). Um estudo feito por Lefrançais e colaboradores mostrou que o pulmão tem função hematopoiética e constitui local terminal da produção de plaquetas. Sendo assim, uma vez que a infecção por SARS-CoV-2 afeta os pulmões, a 
produção de plaquetas fica comprometida (Lefrançais et al. 2017).

Já a incidência de anemia na infecção por COVID-19 frequentemente é baixa, isto pode se relacionar ao aumento da vida útil e à proliferação compensatória dos eritrócitos, induzida por hipóxia associada à pneumonia. Vale ressaltar que a redução da hemoglobina encontra-se mais acentuada nos pacientes com pior desfecho, o qual inclui internação na UTI, necessidade de ventilação invasiva e morte, quando comparados com os não graves (Zhou et al. 2020).

\section{Manifestações cutâneas}

Publicações anteriores descreveram padrões que se assemelham aos da COVID-19 em outras doenças que cursam com síndrome de ativação de macrófagos e/ou hipercitocinemia, como aqueles observados em pacientes com doença de Still, uma enfermidade inflamatória sistêmica rara e de etiologia desconhecida, onde as citocinas atingem a pele e estimulam células dendríticas dérmicas, macrófagos, mastócitos, linfócitos, além das células polimorfonucleares e ainda provocam erupções cutâneas, como eritema, lesões urticárias e vesículas (Criado et al. 2012). Tais lesões exantematosas se confundem com outros exantemas virais, no entanto, a descrição das lesões em suspeitos de COVID-19 parece ser de pouca utilidade para o diagnóstico (Galvan Casas et al. 2020).

Magro e colaboradores empregando a técnica de imuno-histoquímica, encontraram deposição de complemento C5b-9 e C4d em capilares de tecidos com púrpura retiforme em indivíduos com COVID-19. Isso pode representar um papel importante na patogenicidade, uma vez que glicoproteínas S de SARS-CoV-2 foram localizadas adjacentemente à componentes do complemento no pulmão e na pele (Magro et al. 2020).

Como a coagulopatia é um fenômeno presente nas manifestações proporcionadas pela infecção do SARS-CoV-2, manifestações do tipo livedo racemosa, púrpura retiforme e acroisquemia podem ser encontradas nestes pacientes (Magro et al. 2020; Llamas-Velasco et al. 2020).

\section{Manifestações Obstétricas}

O sistema imune materno enfrenta grandes desafios para estabelecer e manter a tolerância ao feto alogênico preservando a capacidade de proteção frente aos microbianos. Uma gravidez bemsucedida depende de adaptações imunes afinadas, tanto sistemicamente quanto localmente. Ao invés de manter a supressão imunológica, os estados imunológicos maternos se adaptam e mudam ativamente com o crescimento e o desenvolvimento do feto em diferentes estágios gestacionais. De um estado pró-inflamatório que é benéfico para a implantação e placentação de embriões no primeiro trimestre, a um estado inflamatório útil para o crescimento fetal no segundo trimestre e, finalmente, atingindo um segundo estado próinflamatório quando se prepara para o início do parto no terceiro trimestre (Mor et al 2017).

Durante a gravidez ocorre nos leucócitos periféricos um evento denominado "relógio imunológico". A gravidez induz um aumento progressivo da sinalização STAT5ab endógena através de múltiplos subconjuntos de células T, CD25+ FoxP3+ (células Treg), células T CD4+ e CD8+naive e de memória, e células $T \delta$. $O$ sistema imunitário materno está bem preparado para responder a invasão de patógenos. Células imunes inatas, como células NK e monócitos, respondem mais fortemente a desafios virais, enquanto algumas respostas imunes adaptativas sofrem desregulação durante a gravidez, como a diminuição do número de células $T$ e $B$ (Aghaeepour et al. 2017).

Infecções por SARS-COV-2 durante a gravidez podem aumentar o risco de aborto espontâneo, do parto prematuro e da restrição do crescimento intrauterino. No entanto, como não há evidência forte de transmissão vertical do COVID-19 da mãe para o filho, pode-se dizer que estas complicações da gravidez acontecem por conta dos efeitos diretos do vírus na mãe (Wong et al. 2004).

Ahipercitocinemia, durante a gravidez, se acumula no plasma placentário aumentando os níveis de IL-2, IL-7, IL-10, do estimulador de colônia de granulócitos, IP-10 (proteína 10 induzida por IFN-), da MCP-1 e do TNF- $\alpha$ (Huang et al. 2020). Baseado no conhecimento de que no primeiro trimestre de gravidez as mulheres cursam um determinado estado pró-inflamatório fisiológico, a hipercitocinemia induzida pelo SARS-CoV-2 pode levar este estado à inflamação patológica e prejudicar a gestação (Mor et al. 2017).

Durante a gravidez, o trato respiratório superior tende a ficar edemaciado devido ao alto nível de estrogênio e progesterona, e a restrição da expansão pulmonar torna a gestante mais suscetível a patógenos respiratórios (Racicot \& Mor 2017). Sendo assim, mulheres grávidas podem ser mais predispostas à infecção por COVID-19 do que a 
população em geral. A inflamação materna natural amplificada em resposta ao SARS-Cov-2 pode afetar 0 desenvolvimento do feto e a vida pós-natal. Neste contexto, com a continuidade da pandemia COVID19, mais esforços devem ser feitos para proteger mães e fetos.

\section{Considerações finais}

A extensa produção de conhecimento desde o início da pandemia acerca da resposta imunitária ao SARS-CoV-2 aponta que, nos indivíduos infectados, a proliferação e o dano tecidual ocorrem para além do tecido pulmonar. Dentre os achados sistêmicos foi demonstrado lesão do tecido linfático submucoso do trato gastrointestinal, hemorragias focais renais, edema e degeneração neuronal, degeneração de hepatócitos, manifestações cardiovasculares, hematológicas, cutâneas e obstétricas. Na prática clínica, nota-se que muitos pacientes com COVID-19 gravemente doentes desenvolvem manifestações clínicas típicas de choque, incluindo extremidades frias e pulsos periféricos fracos, mesmo na ausência de hipotensão. Muitos desses pacientes apresentam acidose metabólica grave, indicando possível disfunção da microcirculação. No entanto, alguns apresentam insuficiência hepática e renal, além de lesão pulmonar grave. Esses pacientes atendem aos critérios de diagnóstico de choque séptico de acordo com o Consenso Internacional de Sepsis, mas a infecção por SARS-CoV-2 parece ser a única causa na maioria dos casos. Contudo, uma vez que coronavírus surgem imprevisivelmente e induzem doenças infecciosas potencialmente graves econstituam risco contínuo à saúde humana, a possibilidade de infecções recorrentes sazonais por coronavírus de genótipos distintos estimularem memória imunitária parcial e favorecer o predomínio de casos brandos da doença, deve ser considerada.

\section{Referências}

Acharya, D., Liu, G. \&Gack, M.U. Dysregulation of type I interferon responses in COVID-19. Nat Rev Immunol (2020). https://doi.org/10.1038/s41577-020-0346-x

Adachi, T., Chong, J. M., Nakajima, N., Sano, M., Yamazaki, J., Miyamoto, I., Nishioka, H., Akita, H., Sato, Y., Kataoka, M., Katano, H., Tobiume, M., Sekizuka, T., Itokawa, K., Kuroda, M., \& Suzuki, T. (2020). Clinicopathologic and Immunohistochemical Findings from Autopsy of Patient with COVID-19, Japan. Emerging infectious diseases, 26(9), 10.3201/eid2609.201353. Advance online publication. https://doi.org/10.3201/eid2609.201353

Adapa, S., Aeddula, N. R., Konala, V. M., Chenna, A., Naramala, S., Madhira, B. R., Gayam, V., Balla, M., Muppidi, V., \& Bose, S. (2020). COVID-19 and Renal Failure: Challenges in the Delivery of Renal Replacement Therapy. Journal of clinical medicine research, 12(5), 276-285. https://doi.org/10.14740/jocmr4160

Aghaeepour, N., Ganio, E. A., Mcilwain, D., Tsai, A. S., Tingle, M., Van Gassen, S., Gaudilliere, D. K., Baca, Q., McNeil, L., Okada, R., Ghaemi, M. S., Furman, D., Wong, R. J., Winn, V. D., Druzin, M. L., El-Sayed, Y. Y., Quaintance, C., Gibbs, R., Darmstadt, G. L., Shaw, G. M., ... Gaudilliere, B. (2017). An immune clock of human pregnancy. Science immunology, 2(15), eaan2946. https://doi.org/10.1126/sciimmunol.aan2946

Albini, A., Di Guardo G., Noonan, D. M., Lombardo, M. The SARS-CoV-2 receptor, ACE-2, is expressed on many different cell types: implications for ACE-inhibitor- and angiotensin II receptor blocker-based cardiovascular therapies. Intern Emerg Med [Internet]. 2020;(0123456789). Available from: http://www.ncbi.nlm.nih.gov/pubmed/32430651

Baig, A. M., Khaleeq, A., Ali, U., \&Syeda, H. (2020). Evidence of the COVID-19 Virus Targeting the CNS: Tissue Distribution, Host-Virus Interaction, and Proposed Neurotropic Mechanisms. ACS chemicalneuroscience, 11(7), 995-998.

https://doi.org/10.1021/acschemneuro.0c00122

Barton, Lisa M., et al. "Autópsias COVID-19, Oklahoma, EUA." American Journal of Clinical Pathology, vol. 153, n. 6, 2020, pp. 725-733., https://doi.org/10.1093/ajcp/aqaa062

Batlle, D., Wysocki, J., Soler, M. J., Ranganath, K. Angiotensin-converting enzyme 2: enhancing the degradation of angiotensin II as a potential therapy for diabetic nephropathy. Kidney Int. 2012;81(6):520-528.

https://doi.org/10.1038/ki.2011.381

Behzad, S., Aghaghazvini, L., Radmard, A. R., Gholamrezanezhad, A. Extrapulmonary manifestations of COVID-19: Radiologic and clinical overview. Clin Imaging [Internet]. 2020; Available from: https://doi.org/10.1016/j.clinimag.2020.05.013

Bergsbaken, T., Fink, S. L., \& Cookson, B. T. (2009). Pyroptosis: host cell death and inflammation. Nature reviews.

Microbiology, 7(2), 99-109. https://doi.org/10.1038/nrmicro2070

Blanco-Melo, D., Nilsson-Payant, B. E., Liu, W. C., Uhl, S., Hoagland, D., Møller, R., Jordan, T. X., Oishi, K., Panis, M., Sachs, D., Wang, T. T., Schwartz, R. E., Lim, J. K., Albrecht, R. A., \&tenOever, B. R. (2020). Imbalanced Host Response to SARS-CoV-2

Drives Development of COVID-19. Cell, 181(5), 1036-1045.e9. https://doi.org/10.1016/j.cell.2020.04.026

Bohmwald, K., Gálvez, N., Ríos, M., \&Kalergis, A. M. (2018). Neurologic Alterations Due to Respiratory Virus Infections. Frontiers in cellular neuroscience, 12, 386. https://doi.org/10.3389/fncel.2018.00386 
Böttcher, E., Matrosovich, T., Beyerle, M., Klenk, H. D., Garten, W., \&Matrosovich, M. (2006). Proteolytic activation of influenza viruses by serine proteases TMPRSS2 and HAT from human airway epithelium. Journal of virology, 80(19), 9896-9898. https://doi.org/10.1128/JVI.01118-06

Channappanavar, R., Fehr, A. R., Vijay, R., Mack, M., Zhao, J., Meyerholz, D. K., \& Perlman, S. (2016). Dysregulated Type I Interferon and Inflammatory Monocyte-Macrophage Responses Cause Lethal Pneumonia in SARS-CoV-Infected Mice. Cell host \& microbe, 19(2), 181-193. https://doi.org/10.1016/j.chom.2016.01.007

Channappanavar, R., Fett, C., Mack, M., Ten Eyck, P. P., Meyerholz, D. K., \& Perlman, S. (2017). Sex-Based Differences in Susceptibility to Severe Acute Respiratory Syndrome Coronavirus Infection. Journal of immunology (Baltimore, Md. : 1950), 198(10), 4046-4053. https://doi.org/10.4049/jimmunol.1601896

Chen, Y., Feng, Z., Diao, B., Rongshuai, W., Wang, G., Wang, C., Tan, Y., Liu, L., Wang, C., Liu, Y., Liu, Y., Yuan, Z., Wu, Y. (2020). The Novel Severe Acute Respiratory Syndrome Coronavirus 2 (SARS-CoV-2) Directly Decimates Human Spleens and Lymph Nodes. https://doi.org/10.1101/2020.03.27.20045427

Chen Y, Liu Q, Guo D. Emerging coronaviruses: genome structure, replication, and pathogenesis. J Med Virol. 2020;92(4):418-23. https://doi.org/10.1002/jmv.25681

Cheng, H., Wang, Y., \& Wang, G. Q. (2020). Organ-protective effect of angiotensin-converting enzyme 2 and its effect on the prognosis of COVID-19. Journal of medical virology, 92(7), 726-730. https://doi.org/10.1002/jmv.25785

Cheng, Y., Luo, R., Wang, K., Zhang, M., Wang, Z., Dong, L., Li, J., Yao, Y., Ge, S., \& Xu, G. (2020). Kidney disease is associated with in-hospital death of patients with COVID-19. Kidney international, 97(5), 829-838.

https://doi.org/10.1016/j.kint.2020.03.005

Crayne, C. B., Albeituni, S., Nichols, K. E., Cron, R. Q. (2019) The immunology of macrophage activation syndrome. Front Immunol 10:119. https://doi.org/10.3389/fimmu.2019.00119 eCollection 2019

Criado, PR, de Carvalho, JF, Ayabe, LA et al. Urticária e dermografismo em pacientes com doença de Still de início adulto. Rheumatol Int 32, 2551-2555 (2012). https://doi.org/10.1007/s00296-011-2025-5

Desforges, M., Le Coupanec, A., Dubeau, P., Bourgouin, A., Lajoie, L., Dubé, M., \& Talbot, P. J. (2019). Human Coronaviruses and Other Respiratory Viruses: Underestimated Opportunistic Pathogens of the Central Nervous System?. Viruses, 12(1), 14. https://doi.org/10.3390/v12010014

Dhama, K., Sharun, K., Tiwari, R., Sircar,S.; Bhat, S., Malik, Y.S., Singh, K.P.; Chaicumpa, W., Bonilla-Aldana, D.K.; RodriguezMorales, A.J. Coronavirus Disease 2019 \&andash; COVID-19. Preprints, 2020.

Diao, B., Wang, C., Tan, Y., Chen, X., Liu, Y., Ning, L., Chen, L., Li, M., Liu, Y., Wang, G., Yuan, Z., Feng, Z., Wu, Y., Chen, Y. (2020). Reduction and Functional Exhaustion of T Cells in Patients with Coronavirus Disease 2019 (COVID-19). Preprint at medRxivhttps://doi.org/10.1101/2020.02.18.20024364

Donoghue, M., Hsieh, F., Baronas, E., Godbout, K., Gosselin, M., Stagliano, N., Donovan, M., Woolf, B., Robison, K., Jeyaseelan, R., Breitbart, R. E., \& Acton, S. (2000). A novel angiotensin-converting enzyme-related carboxypeptidase (ACE2) converts angiotensin I to angiotensin 1-9. Circulation research, 87(5), E1-E9. https://doi.org/10.1161/01.res.87.5.e1 Finlay, B. B., \& Hancock, R. E. (2004). Can innate immunity be enhanced to treat microbial infections?. Nature reviews. Microbiology, 2(6), 497-504. https://doi.org/10.1038/nrmicro908

Fodoulian, L., Tuberosa, J., Rossier, D., Landis, B., Carleton, A., Rodriguez, I. (2020). SARS-CoV-2 receptor and entry genes are expressed by sustentacular cells in the human olfactory neuroepithelium. bioRxiv.

https://doi.org/10.1101/2020.03.31.013268

Gemmati, D., Bramanti, B., Serino, M. L., Secchiero, P., Zauli, G., Tisato, V. (2020) COVID-19 and Individual Genetic Susceptibility/Receptivity: Role of ACE1/ACE2 Genes, Immunity, Inflammation and Coagulation. Might the Double Xchromosome in Females Be Protective against SARS-CoV-2 Compared to the Single X-Chromosome in Males?. Int J Mol Sci.;21(10):E3474. Published 2020 May 14. https://doi.org/10.3390/ijms21103474

Golonka, R. M., Saha, P., Yeoh, B. S., Chattopadhyay, S., Gewirtz, A. T., Joe, B., \& Vijay-Kumar, M. (2020). Harnessing innate immunity to eliminate SARS-CoV-2 and ameliorate COVID-19 disease. Physiological genomics, 52(5), $217-221$.

https://doi.org/10.1152/physiolgenomics.00033.2020

Graham, R. L., Donaldson, E. F., \& Baric, R. S. (2013). A decade after SARS: strategies for controlling emerging coronaviruses. Nature reviews. Microbiology, 11(12), 836-848. https://doi.org/10.1038/nrmicro3143

Gralinski, L. E., Sheahan, T. P., Morrison, T. E., Menachery, V. D., Jensen, K., Leist, S. R., Whitmore, A., Heise, M. T., \& Baric, R. S. (2018). Complement Activation Contributes to Severe Acute Respiratory Syndrome Coronavirus Pathogenesis. mBio, 9(5), e01753-18. https://doi.org/10.1128/mBio.01753-18

Gu, J., Gong, E., Zhang, B., Zheng, J., Gao, Z., Zhong, Y., Zou, W., Zhan, J., Wang, S., Xie, Z., Zhuang, H., Wu, B., Zhong, H., Shao, H., Fang, W., Gao, D., Pei, F., Li, X., He, Z., Xu, D., ... Leong, A. S. (2005). Multiple organ infection and the pathogenesis of SARS. The Journal of experimental medicine, 202(3), 415-424. https://doi.org/10.1084/jem.20050828

Guan, W. J., Ni, Z. Y., Hu, Y., Liang, W. H., Ou, C. Q., He, J. X., Liu, L., Shan, H., Lei, C. L., Hui, D., Du, B., Li, L. J., Zeng, G., Yuen, K. Y., Chen, R. C., Tang, C. L., Wang, T., Chen, P. Y., Xiang, J., Li, S. Y., ... China Medical Treatment Expert Group for Covid-19 
(2020). Clinical Characteristics of Coronavirus Disease 2019 in China. The New England journal of medicine, 382(18), 1708-1720. https://doi.org/10.1056/NEJMoa2002032

Hamming, I., Timens, W., Bulthuis, M. L., Lely, A. T., Navis, G., \& van Goor, H. (2004). Tissue distribution of ACE2 protein, the functional receptor for SARS coronavirus. A first step in understanding SARS pathogenesis. The Journal of pathology, 203(2), 631-637. https://doi.org/10.1002/path.1570

Harmer, D., Gilbert, M., Borman, R., \& Clark, K. L. (2002). Quantitative mRNA expression profiling of ACE 2, a novel homologue of angiotensin converting enzyme. FEBS letters, 532(1-2), 107-110. https://doi.org/10.1016/s00145793(02)03640-2

Haznedaroglu, I. C., \&Beyazit, Y. (2013). Local bone marrow renin-angiotensin system in primitive, definitive and neoplastic haematopoiesis. Clinical science (London, England : 1979), 124(5), 307-323. https://doi.org/10.1042/CS20120300 He, L., Ding, Y., Zhang, Q., Che, X., He, Y., Shen, H., Wang, H., Li, Z., Zhao, L., Geng, J., Deng, Y., Yang, L., Li, J., Cai, J., Qiu, L., Wen, K., Xu, X., \& Jiang, S. (2006). Expression of elevated levels of pro-inflammatory cytokines in SARS-CoV-infected ACE2+ cells in SARS patients: relation to the acute lung injury and pathogenesis of SARS. The Journal of pathology, 210(3), 288-297. https://doi.org/10.1002/path.2067

Hoffmann, M., Kleine-Weber, H., Schroeder, S., Krüger, N., Herrler, T., Erichsen, S., Schiergens, T. S., Herrler, G., Wu, N. H., Nitsche, A., Müller, M. A., Drosten, C., \&Pöhlmann, S. (2020). SARS-CoV-2 Cell Entry Depends on ACE2 and TMPRSS2 and Is Blocked by a Clinically Proven Protease Inhibitor. Cell, 181(2), 271-280.e8. https://doi.org/10.1016/j.cell.2020.02.052 Huang, C., Wang, Y., Li, X., Ren, L., Zhao, J., Hu, Y., Zhang, L., Fan, G., Xu, J., Gu, X., Cheng, Z., Yu, T., Xia, J., Wei, Y., Wu, W., Xie, X., Yin, W., Li, H., Liu, M., Xiao, Y., ... Cao, B. (2020). Clinical features of patients infected with 2019 novel coronavirus in Wuhan, China. Lancet (London, England), 395(10223), 497-506. https://doi.org/10.1016/S0140-6736(20)30183-5 Puelles, V. G., Lütgehetmann, M., Lindenmeyer, M. T., Sperhake, J. P., Wong, M. N., Allweiss, L., Chilla, S., Heinemann, A., Wanner, N., Liu, S., Braun, F., Lu, S., Pfefferle, S., Schröder, A. S., Edler, C., Gross, O., Glatzel, M., Wichmann, D., Wiech, T., Kluge, S., ... Huber, T. B. (2020). Multiorgan and Renal Tropism of SARS-CoV-2. The New England journal of medicine, NEJMc2011400. Advance online publication. https://doi.org/10.1056/NEJMc2011400 Imai, Y., Kuba, K., Rao, S. et al. Angiotensin-converting enzyme 2 protects from severe acute lung failure. Nature 436, 112-116 (2005). https://doi.org/10.1038/nature03712

Jia, H. P., Look, D. C., Shi, L., Hickey, M., Pewe, L., Netland, J., Farzan, M., Wohlford-Lenane, C., Perlman, S., McCray, P. B. Jr. (2005) ACE2 Receptor Expression and Severe Acute Respiratory Syndrome Coronavirus Infection Depend on Differentiation of Human Airway Epithelia. Journal of Virology, Dec. 2005, p. 14614-14621 Vol. 79, No. 23 0022-538X/05/\$08.000 https://doi.org/10.1128/JVI.79.23.14614-14621.2005

Kaplan, M. J., \&Radic, M. (2012). Neutrophil extracellular traps: double-edged swords of innate immunity. Journal of immunology (Baltimore, Md. : 1950), 189(6), 2689-2695. https://doi.org/10.4049/jimmunol.1201719

Kissler, S. M., Tedijanto, C., Goldstein, E., Grad, Y. H., \&Lipsitch, M. (2020). Projecting the transmission dynamics of SARS-CoV2 through the postpandemic period. Science (New York, N.Y.), 368(6493), 860-868. https://doi.org/10.1126/science.abb5793 Kovats S. (2015). Estrogen receptors regulate innate immune cells and signaling pathways. Cellular immunology, 294(2), 63-69. https://doi.org/10.1016/j.cellimm.2015.01.018

Kuba, K., Imai, Y., Rao, S., Gao, H., Guo, F., Guan, B., Huan, Y., Yang, P., Zhang, Y., Deng, W., Bao, L., Zhang, B., Liu, G., Wang, Z., Chappell, M., Liu, Y., Zheng, D., Leibbrandt, A., Wada, T., Slutsky, A. S., ... Penninger, J. M. (2005). A crucial role of angiotensin converting enzyme 2 (ACE2) in SARS coronavirus-induced lung injury. Nature medicine, 11(8), 875-879.

https://doi.org/10.1038/nm1267

Liu, K., Fang, Y. Y., Deng, Y., Liu, W., Wang, M. F., Ma, J. P., Xiao, W., Wang, Y. N., Zhong, M. H., Li, C. H., Li, G. C., \& Liu, H. G. (2020). Clinical characteristics of novel coronavirus cases in tertiary hospitals in Hubei Province. Chinese medical journal, 133(9), 1025-1031. https://doi.org/10.1097/CM9.0000000000000744

Kumar S, Maurya VK, Prasad AK et al (2020) Structural, glycosylation and antigenic variation between 2019 novel coronavirus (2019-nCoV) and SARS coronavirus (SARS-CoV). VirusDis 31(1):13-21. https://doi.org/10.1007/s13337-020-00571-5 Lefèvre, N., Corazza, F., Valsamis, J., Delbaere, A., De Maertelaer, V., Duchateau, J., \&Casimir, G. (2019). The Number of X Chromosomes Influences Inflammatory Cytokine Production Following Toll-Like Receptor Stimulation. Frontiers in immunology, 10, 1052. https://doi.org/10.3389/fimmu.2019.01052

Lefrançais, E., Ortiz-Muñoz, G., Caudrillier, A., Mallavia, B., Liu, F., Sayah, D. M., Thornton, E. E., Headley, M. B., David, T., Coughlin, S. R., Krummel, M. F., Leavitt, A. D., Passegué, E., \& Looney, M. R. (2017). The lung is a site of platelet biogenesis and a reservoir for haematopoietic progenitors. Nature, 544(7648), 105-109. https://doi.org/10.1038/nature21706 Li, G., Fan, Y., Lai, Y., Han, T., Li, Z., Zhou, P., Pan, P., Wang, W., Hu, D., Liu, X., Zhang, Q., \& Wu, J. (2020). Coronavirus infections and immune responses. Journal of medical virology, 92(4), 424-432. https://doi.org/10.1002/jmv.25685 Li, G., He, X., Zhang, L., Ran, Q., Wang, J., Xiong, A., Wu, D., Chen, F., Sun, J., \& Chang, C. (2020). Assessing ACE2 expression patterns in lung tissues in the pathogenesis of COVID-19. Journal of autoimmunity, 102463. Advance online publication. https://doi.org/10.1016/j.jaut.2020.102463 Li, J., \& Fan, J. G. (2020). Characteristics and Mechanism of Liver Injury in 2019 Coronavirus Disease. Journal of clinical and 
translational hepatology, 8(1), 13-17. https://doi.org/10.14218/JCTH.2020.00019

Li, L. Y., Wu, W., Chen, S., Gu, J. W., Li, X. L., Song, H. J., Du, F., Wang, G., Zhong, C. Q., Wang, X. Y., Chen, Y., Shah, R., Yang, H. M., \& Cai, Q. (2020). Digestive system involvement of novel coronavirus infection: Prevention and control infection from a gastroenterology perspective. Journal of digestive diseases, 21(4), 199-204. https://doi.org/10.1111/1751-2980.12862 Li, T., Qiu, Z., Han, Y., Wang, Z., Fan, H., Lu, W., Xie, J., Ma, X., \& Wang, A. (2003). Rapid loss of both CD4+ and CD8+ T lymphocyte subsets during the acute phase of severe acute respiratory syndrome. Chinese medical journal, 116(7), 985-987.

Li, W., Sui, J., Huang, I. C., Kuhn, J. H., Radoshitzky, S. R., Marasco, W. A., Choe, H., \& Farzan, M. (2007). The S proteins of human coronavirus NL63 and severe acute respiratory syndrome coronavirus bind overlapping regions of ACE2. Virology, 367(2), 367-374. https://doi.org/10.1016/j.virol.2007.04.035

Li, S. R., Tang, Z. J., Li, Z. H., \& Liu, X. (2020). Searching therapeutic strategy of new coronavirus pneumonia from angiotensin-converting enzyme 2: the target of COVID-19 and SARS-CoV. European journal of clinical microbiology \& infectious diseases : official publication of the European Society of Clinical Microbiology, 39(6), 1021-1026.

https://doi.org/10.1007/s10096-020-03883-y

Li, T., Qiu, Z., Zhang, L., Han, Y., He, W., Liu, Z., Ma, X., Fan, H., Lu, W., Xie, J., Wang, H., Deng, G., \& Wang, A. (2004). Significant changes of peripheral T lymphocyte subsets in patients with severe acute respiratory syndrome. The Journal of infectious diseases, 189(4), 648-651. https://doi.org/10.1086/381535

Liu, J., Zheng, X., Tong, Q., Li, W., Wang, B., Sutter, K., Trilling, M., Lu, M., Dittmer, U., \& Yang, D. (2020). Overlapping and discrete aspects of the pathology and pathogenesis of the emerging human pathogenic coronaviruses SARS-CoV, MERSCoV, and 2019-nCoV. Journal of medical virology, 92(5), 491-494. https://doi.org/10.1002/jmv.25709

Liu, J., Liu, Y., Xiang, P., Pu, L., Xiong, H., Li, C... (2020) Neutrophil-to-lymphocyte ratio predicts severe illness patients with 2019 novel coronavirus in the early stage. medRxiv. https://doi.org/10.1101/2020.02.10.20021584

Liu, L., Wei, Q., Lin, Q., Fang, J., Wang, H., Kwok, H., Tang, H., Nishiura, K., Peng, J., Tan, Z., Wu, T., Cheung, K. W., Chan, K. H., Alvarez, X., Qin, C., Lackner, A., Perlman, S., Yuen, K. Y., \& Chen, Z. (2019). Anti-spike IgG causes severe acute lung injury by skewing macrophage responses during acute SARS-CoV infection. JCl insight, 4(4), e123158.

https://doi.org/10.1172/jci.insight.123158

Llamas-Velasco, M., Muñoz-Hernández, P., Lázaro-González, J., Reolid-Pérez, A., Abad-Santamaría, B., Fraga, J., \&DaudénTello, E. (2020). Thrombotic occlusive vasculopathy in skin biopsy from a livedoid lesion of a COVID-19 patient. The British journal of dermatology, 10.1111/bjd.19222. Advance online publication. https://doi.org/10.1111/bjd.19222

Madjid, M., Safavi-Naeini, P., Solomon, S. D., \&Vardeny, O. (2020). Potential Effects of Coronaviruses on the Cardiovascular System: A Review. JAMA cardiology, 10.1001/jamacardio.2020.1286. Advance online publication.

https://doi.org/10.1001/jamacardio.2020.1286

Magro, C., Mulvey, J. J., Berlin, D., Nuovo, G., Salvatore, S., Harp, J., Baxter-Stoltzfus, A., \& Laurence, J. (2020). Complement associated microvascular injury and thrombosis in the pathogenesis of severe COVID-19 infection: A report of five cases. Translational research : the journal of laboratory and clinical medicine, 220, 1-13.

https://doi.org/10.1016/j.trsl.2020.04.007

Maloir, Q., Ghysen, K., von Frenckell, C., Louis, R., \&Guiot, J. (2018). Détresserespiratoireaiguërévélatrice d'un syndrome des antisynthétases [Acute respiratory distress revealing antisynthetase syndrome]. Revue medicale de Liege, 73(7-8), 370-375. Marchandot, B., Sattler, L., Jesel, L., Matsushita, K., Schini-Kerth, V., Grunebaum, L., \& Morel, O. (2020). COVID-19 Related Coagulopathy: A Distinct Entity?. Journal of clinical medicine, 9(6), E1651. https://doi.org/10.3390/jcm9061651

Martines, R. B., Ritter, J. M., Matkovic, E., Gary, J., Bollweg, B. C., Bullock, H., Goldsmith, C. S., Silva-Flannery, L., Seixas, J. N., Reagan-Steiner, S., Uyeki, T., Denison, A., Bhatnagar, J., Shieh, W. J., Zaki, S. R., \& COVID-19 Pathology Working Group (2020). Pathology and Pathogenesis of SARS-CoV-2 Associated with Fatal Coronavirus Disease, United States. Emerging infectious diseases, 26(9), 10.3201/eid2609.202095. Advance online publication. https://doi.org/10.3201/eid2609.202095 Menter, T., Haslbauer, J. D., Nienhold, R., Savic, S., Hopfer, H., Deigendesch, N., Frank, S., Turek, D., Willi, N., Pargger, H., Bassetti, S., Leuppi, J. D., Cathomas, G., Tolnay, M., Mertz, K. D., \&Tzankov, A. (2020). Post-mortem examination of COVID19 patients reveals diffuse alveolar damage with severe capillary congestion and variegated findings of lungs and other organs suggesting vascular dysfunction. Histopathology, 10.1111/his.14134. Advance online publication.

https://doi.org/10.1111/his.14134

Min, C. K., Cheon, S., Ha, N. Y., Sohn, K. M., Kim, Y., Aigerim, A., Shin, H. M., Choi, J. Y., Inn, K. S., Kim, J. H., Moon, J. Y., Choi, M. S., Cho, N. H., \& Kim, Y. S. (2016). Comparative and kinetic analysis of viral shedding and immunological responses in MERS patients representing a broad spectrum of disease severity. Scientific reports, 6, 25359.

https://doi.org/10.1038/srep25359

Mor, G., Aldo, P., \&Alvero, A. B. (2017). The unique immunological and microbial aspects of pregnancy. Nature reviews. Immunology, 17(8), 469-482. https://doi.org/10.1038/nri.2017.64

Morgan, K., Samuel, K., Vandeputte, M., Hayes, P. C., \&Plevris, J. N. (2020). SARS-CoV-2 Infection and the Liver. Pathogens (Basel, Switzerland), 9(6), E430. https://doi.org/10.3390/pathogens9060430 
Moulton V. R. (2018). Sex Hormones in Acquired Immunity and Autoimmune Disease. Frontiers in immunology, 9, 2279. https://doi.org/10.3389/fimmu.2018.02279

Musa S. Hepatic and gastrointestinal involvement in coronavirus disease 2019 (COVID-19): What do we know till now? Arab J Gastroenterol [Internet]. 2020;21(1):3-8. Available from: https://doi.org/10.1016/j.ajg.2020.03.002 Onyeaka, H. K., Zahid, S., \& Patel, R. S. (2020). The Unaddressed Behavioral Health Aspect During the Coronavirus Pandemic. Cureus, 12(3), e7351. https://doi.org/10.7759/cureus.7351

Pan, L., Mu, M., Yang, P., Sun, Y., Wang, R., Yan, J., Li, P., Hu, B., Wang, J., Hu, C., Jin, Y., Niu, X., Ping, R., Du, Y., Li, T., Xu, G., Hu, Q., \& Tu, L. (2020). Clinical Characteristics of COVID-19 Patients With Digestive Symptoms in Hubei, China: A Descriptive, Cross-Sectional, Multicenter Study. The American journal of gastroenterology, 115(5), 766-773. https://doi.org/10.14309/ajg.0000000000000620

Paules, C. I., Marston, H. D., \&Fauci, A. S. (2020). Coronavirus Infections-More Than Just the Common Cold. JAMA, 10.1001/jama.2020.0757. Advance online publication. https://doi.org/10.1001/jama.2020.0757

Peiris, J. S., Yuen, K. Y., Osterhaus, A. D., \&Stöhr, K. (2003). The severe acute respiratory syndrome. The New England journal of medicine, 349(25), 2431-2441. https://doi.org/10.1056/NEJMra032498

Peng, L., Liu, J., Xu, W., Luo, Q., Chen, D., Lei, Z., Huang, Z., Li, X., Deng, K., Lin, B., \& Gao, Z. (2020). SARS-CoV-2 can be detected in urine, blood, anal swabs, and oropharyngeal swabs specimens. Journal of medical virology,

10.1002/jmv.25936. Advance online publication. https://doi.org/10.1002/jmv.25936

Poyiadji, N., Shahin, G., Noujaim, D., Stone, M., Patel, S., \& Griffith, B. (2020). COVID-19-associated Acute Hemorrhagic Necrotizing Encephalopathy: CT and MRI Features. Radiology, 201187. Advance online publication.

https://doi.org/10.1148/radiol.2020201187

Qin, C., Zhou, L., Hu, Z., Zhang, S., Yang, S., Tao, Y., Xie, C., Ma, K., Shang, K., Wang, W., \& Tian, D. S. (2020). Dysregulation of immune response in patients with COVID-19 in Wuhan, China. Clinical infectious diseases : an official publication of the Infectious Diseases Society of America, ciaa248. Advance online publication. https://doi.org/10.1093/cid/ciaa248

Racicot, K., \&Mor, G. (2017). Risks associated with viral infections during pregnancy. The Journal of clinical investigation, 127(5), 1591-1599. https://doi.org/10.1172/JCl87490

Read R (2020) Flawed methods in "COVID-19: attacks the 1-beta chain of hemoglobin and captures the porphyrin to inhibit human heme metabolism". ChemRxiv Preprint. https://doi.org/10.26434/chemrxiv.12120912.v1

Sharifi-Razavi, A., Karimi, N., \& Rouhani, N. (2020). COVID-19 and intracerebral haemorrhage: causative or coincidental?. New microbes and new infections, 35, 100669. https://doi.org/10.1016/j.nmni.2020.100669

Shen, X. Z., Okwan-Duodu, D., Blackwell, W. L., Ong, F. S., Janjulia, T., Bernstein, E. A., Fuchs, S., Alkan, S., \& Bernstein, K. E. (2014). Myeloid expression of angiotensin-converting enzyme facilitates myeloid maturation and inhibits the development of myeloid-derived suppressor cells. Laboratory investigation; a journal of technical methods and pathology, 94(5),

536-544. https://doi.org/10.1038/labinvest.2014.41

Snijder, E. J., van der Meer, Y., Zevenhoven-Dobbe, J., Onderwater, J. J., van der Meulen, J., Koerten, H. K., \&Mommaas, A. M. (2006). Ultrastructure and origin of membrane vesicles associated with the severe acute respiratory syndrome coronavirus replication complex. Journal of virology, 80(12), 5927-5940. https://doi.org/10.1128/JVI.02501-05

Stopsack, K. H., Mucci, L. A., Antonarakis, E. S., Nelson, P. S., \&Kantoff, P. W. (2020). TMPRSS2 and COVID-19: Serendipity or Opportunity for Intervention?. Cancer discovery, 10(6), 779-782. https://doi.org/10.1158/2159-8290.CD-20-0451 Su, H., Yang, M., Wan, C., Yi, L. X., Tang, F., Zhu, H. Y., Yi, F., Yang, H. C., Fogo, A. B., Nie, X., \& Zhang, C. (2020). Renal histopathological analysis of 26 postmortem findings of patients with COVID-19 in China. Kidney international, 98(1), 219-227. Advance online publication. https://doi.org/10.1016/j.kint.2020.04.003

Su, M., Peng, J., Wu, M., Deng, W., Yang, Y., \& Peng, Y. G. (2020). Two consecutive myocardial tissue insults for inpatients with COVID-19. Critical care (London, England), 24(1), 259. https://doi.org/10.1186/s13054-020-02981-9

Sun, J., Zhu, A., Li, H., Zheng, K., Zhuang, Z., Chen, Z., Shi, Y., Zhang, Z., Chen, S. B., Liu, X., Dai, J., Li, X., Huang, S., Huang, X., Luo, L., Wen, L., Zhuo, J., Li, Y., Wang, Y., Zhang, L., ... Li, Y. M. (2020). Isolation of infectious SARS-CoV-2 from urine of a COVID-19 patient. Emerging microbes \& infections, 9(1), 991-993. https://doi.org/10.1080/22221751.2020.1760144 Tait, S. W., Ichim, G., \& Green, D. R. (2014). Die another way--non-apoptotic mechanisms of cell death. Journal of cell science, 127(Pt 10), 2135-2144. https://doi.org/10.1242/jcs.093575

Tipnis, S. R., Hooper, N. M., Hyde, R., Karran, E., Christie, G., \& Turner, A. J. (2000). A human homolog of angiotensinconverting enzyme. Cloning and functional expression as a captopril-insensitive carboxypeptidase. The Journal of biological chemistry, 275(43), 33238-33243. https://doi.org/10.1074/jbc.M002615200

Varga, Z., Flammer, A. J., Steiger, P., Haberecker, M., Andermatt, R., Zinkernagel, A. S., Mehra, M. R., Schuepbach, R. A., Ruschitzka, F., \&Moch, H. (2020). Endothelial cell infection and endotheliitis in COVID-19. Lancet (London, England), 395(10234), 1417-1418. https://doi.org/10.1016/S0140-6736(20)30937-5

Wang, D., Hu, B., Hu, C., Zhu, F., Liu, X., Zhang, J., Wang, B., Xiang, H., Cheng, Z., Xiong, Y., Zhao, Y., Li, Y., Wang, X., \& Peng, Z. (2020). Clinical Characteristics of 138 Hospitalized Patients With 2019 Novel Coronavirus-Infected Pneumonia in Wuhan, China. JAMA, 323(11), 1061-1069. Advance online publication. https://doi.org/10.1001/jama.2020.1585 
Wang, Y., Wang, Y., Chen, Y., \& Qin, Q. (2020). Unique epidemiological and clinical features of the emerging 2019 novel coronavirus pneumonia (COVID-19) implicate special control measures. Journal of medical virology, 92(6), 568-576. https://doi.org/10.1002/jmv.25748

Wang, X., Xu, W., Hu, G. et al. SARS-CoV-2 infects T lymphocytes through its spike protein-mediated membrane fusion. Cell Mol Immunol (2020). https://doi.org/10.1038/s41423-020-0424-9

Weiss, S. R., \& Leibowitz, J. L. (2011). Coronavirus pathogenesis. Advances in virus research, 81, 85-164.

https://doi.org/10.1016/B978-0-12-385885-6.00009-2

Wenzhong, L., Hualan, L. (2020): COVID-19:Attacks the 1-Beta Chain of Hemoglobin and Captures the Porphyrin to Inhibit Human Heme Metabolism. ChemRxiv. Preprint. https://doi.org/10.26434/chemrxiv.11938173.v8

Wichmann, D., Sperhake, J. P., Lütgehetmann, M., Steurer, S., Edler, C., Heinemann, A., Heinrich, F., Mushumba, H., Kniep, I., Schröder, A. S., Burdelski, C., de Heer, G., Nierhaus, A., Frings, D., Pfefferle, S., Becker, H., Bredereke-Wiedling, H., de Weerth, A., Paschen, H. R., Sheikhzadeh-Eggers, S., ... Kluge, S. (2020). Autopsy Findings and Venous Thromboembolism in Patients With COVID-19. Annals of internal medicine, M20-2003. Advance online publication.

https://doi.org/10.7326/M20-2003

Wong, R. S., Wu, A., To, K. F., Lee, N., Lam, C. W., Wong, C. K., Chan, P. K., Ng, M. H., Yu, L. M., Hui, D. S., Tam, J. S., Cheng, G., \& Sung, J. J. (2003). Haematological manifestations in patients with severe acute respiratory syndrome: retrospective analysis. BMJ (Clinical research ed.), 326(7403), 1358-1362. https://doi.org/10.1136/bmj.326.7403.1358

Wong, S. F., Chow, K. M., Leung, T. N., Ng, W. F., Ng, T. K., Shek, C. C., Ng, P. C., Lam, P. W., Ho, L. C., To, W. W., Lai, S. T., Yan, W. W., \& Tan, P. Y. (2004). Pregnancy and perinatal outcomes of women with severe acute respiratory syndrome. American journal of obstetrics and gynecology, 191(1), 292-297. https://doi.org/10.1016/j.ajog.2003.11.019

Wu, C., Chen, X., Cai, Y., Xia, J., Zhou, X., Xu, S., Huang, H., Zhang, L., Zhou, X., Du, C., Zhang, Y., Song, J., Wang, S., Chao, Y., Yang, Z., Xu, J., Zhou, X., Chen, D., Xiong, W., Xu, L., ... Song, Y. (2020). Risk Factors Associated With Acute Respiratory Distress Syndrome and Death in Patients With Coronavirus Disease 2019 Pneumonia in Wuhan, China. JAMA internal medicine, e200994. Advance online publication. https://doi.org/10.1001/jamainternmed.2020.0994

Wu, Y., Guo, C., Tang, L., Hong, Z., Zhou, J., Dong, X., Yin, H., Xiao, Q., Tang, Y., Qu, X., Kuang, L., Fang, X., Mishra, N., Lu, J., Shan, H., Jiang, G., \& Huang, X. (2020). Prolonged presence of SARS-CoV-2 viral RNA in faecal samples. The lancet.

Gastroenterology \& hepatology, 5(5), 434-435. https://doi.org/10.1016/S2468-1253(20)30083-2

Wu Y. (2020). Compensation of ACE2 Function for Possible Clinical Management of 2019-nCoV-Induced Acute Lung Injury. VirologicaSinica, 1-3. Advance online publication. https://doi.org/10.1007/s12250-020-00205-6

Xu, Z., Shi, L., Wang, Y., Zhang, J., Huang, L., Zhang, C., Liu, S., Zhao, P., Liu, H., Zhu, L., Tai, Y., Bai, C., Gao, T., Song, J., Xia, P., Dong, J., Zhao, J., \& Wang, F. S. (2020). Pathological findings of COVID-19 associated with acute respiratory distress syndrome. The Lancet. Respiratory medicine, 8(4), 420-422. https://doi.org/10.1016/S2213-2600(20)30076-X Yan, R., Zhang, Y., Li, Y., Xia, L., Guo, Y., \& Zhou, Q. (2020). Structural basis for the recognition of SARS-CoV-2 by full-length human ACE2. Science (New York, N.Y.), 367(6485), 1444-1448. https://doi.org/10.1126/science.abb2762

Yang, M. Cell Pyroptosis, a Potential Pathogenic Mechanism of 2019-nCoV Infection (January 29, 2020). Available at SSRN: https://ssrn.com/abstract=3527420 or http://dx.doi.org/10.2139/ssrn.3527420

Yao, X. H., Li, T. Y., He, Z. C., Ping, Y. F., Liu, H. W., Yu, S. C., Mou, H. M., Wang, L. H., Zhang, H. R., Fu, W. J., Luo, T., Liu, F., Guo, Q. N., Chen, C., Xiao, H. L., Guo, H. T., Lin, S., Xiang, D. F., Shi, Y., Pan, G. Q., ... Bian, X. W. (2020). A Pathological Report of Three COVID-19 Cases by Minimal Invasive Autopsies. Zhonghuabing li xue za zhi = Chinese journal of pathology, 49(5), 411-417. https://doi.org/10.3760/cma.j.cn112151-20200312-00193

Troyer, E. A., Kohn, J. N., \& Hong, S. (2020). Are we facing a crashing wave of neuropsychiatric sequelae of COVID-19? Neuropsychiatric symptoms and potential immunologic mechanisms. Brain, behavior, and immunity, 87, 34-39. Advance online publication. https://doi.org/10.1016/j.bbi.2020.04.027

Zhang, J., Wang, S., \&Xue, Y. (2020). Fecal specimen diagnosis 2019 novel coronavirus-infected pneumonia. Journal of medical virology, 92(6), 680-682. https://doi.org/10.1002/jmv.25742

Zhang, W., Zhao, Y., Zhang, F., Wang, Q., Li, T., Liu, Z., Wang, J., Qin, Y., Zhang, X., Yan, X., Zeng, X., \& Zhang, S. (2020). The use of anti-inflammatory drugs in the treatment of people with severe coronavirus disease 2019 (COVID-19): The Perspectives of clinical immunologists from China. Clinical immunology (Orlando, Fla.), 214, 108393.

https://doi.org/10.1016/j.clim.2020.108393

Zhang, Y., Xiao, M., Zhang, S., Xia, P., Cao, W., Jiang, W., Chen, H., Ding, X., Zhao, H., Zhang, H., Wang, C., Zhao, J., Sun, X., Tian, R., Wu, W., Wu, D., Ma, J., Chen, Y., Zhang, D., Xie, J., ... Zhang, S. (2020). Coagulopathy and Antiphospholipid

Antibodies in Patients with Covid-19. The New England journal of medicine, 382(17), e38.

https://doi.org/10.1056/NEJMc2007575

Zhao, J., Yuan, Q., Wang, H., Liu, W., Liao, X., Su, Y., Wang, X., Yuan, J., Li, T., Li, J., Qian, S., Hong, C., Wang, F., Liu, Y., Wang, Z., He, Q., Li, Z., He, B., Zhang, T., Fu, Y., ... Zhang, Z. (2020). Antibody responses to SARS-CoV-2 in patients of novel coronavirus disease 2019. Clinical infectious diseases : an official publication of the Infectious Diseases Society of America, ciaa344. Advance online publication. https://doi.org/10.1093/cid/ciaa344 
Zheng, M., Gao, Y., Wang, G., Song, G., Liu, S., Sun, D., Xu, Y., \& Tian, Z. (2020). Functional exhaustion of antiviral lymphocytes in COVID-19 patients. Cellular \& molecular immunology, 17(5), 533-535. https://doi.org/10.1038/s41423020-0402-2

Zhou, Y. G., Fu, B. Q., Zheng, X. H., Wang, D. S., Zhao, C. C,, Qi, Y. J... (2020) Aberrant pathogenic GM-CSF+ T cells and inflammatory CD14+CD16+ monocytes in severe pulmonary syndrome patients of a new coronavirus. bioRxiv. https://doi.org/10.1101/2020.02.12. 945576

Zhou, F., Yu, T., Du, R., Fan, G., Liu, Y., Liu, Z., Xiang, J., Wang, Y., Song, B., Gu, X., Guan, L., Wei, Y., Li, H., Wu, X., Xu, J., Tu, S., Zhang, Y., Chen, H., \&Cao, B. (2020). Clinical course and risk factors for mortality of adult inpatients with COVID-19 in Wuhan, China: a retrospective cohort study. Lancet (London, England), 395(10229), 1054-1062. https://doi.org/10.1016/S0140-6736(20)30566-3 Zhu, N., Zhang, D., Wang, W., Li, X., Yang, B., Song, J., Zhao, X., Huang, B., Shi, W., Lu, R., Niu, P., Zhan, F., Ma, X., Wang, D., Xu, W., Wu, G., Gao, G. F., Tan, W., \& China Novel Coronavirus Investigating and Research Team (2020). A Novel Coronavirus from Patients with Pneumonia in China, 2019. The New England journal of medicine, 382(8), 727-733. https://doi.org/10.1056/NEJMoa2001017 Zorzetto, R. Os danos do coronavírus. Pesquisa FAPESP, São Paulo, 01 de abril de 2020. Disponivel em: https://revistapesquisa.fapesp.br/os-danos-do-coronavirus/. Acesso em 08 de junho de 2020.

Zou, X., Chen, K., Zou, J., Han, P., Hao, J., \& Han, Z. (2020). Single-cell RNA-seq data analysis on the receptor ACE2 expression reveals the potential risk of different human organs vulnerable to 2019-nCoV infection. Frontiers of medicine, 14(2), 185-192. https://doi.org/10.1007/s11684-020-0754-0 